\title{
Mechanism of Gastroesophageal Reflux in Recumbent Asymptomatic Human Subjects
}

\author{
John Dent, Wylie J. Dodds, Robert H. Friedman, Toshikazu Sekiguchi, \\ Walter J. Hogan, Ronald C. Arndorfer, and Dennis J. Petrie, \\ Departments of Radiology, Medicine, and Neurology, The Medical College of \\ Wisconsin, Milwaukee, Wisconsin 53226
}

\begin{abstract}
A B S T R A C T We investigated the mechanism of gastroesophageal reflux (GER) in 10 healthy volunteer subjects. Continuous recordings of intraluminal esophageal $\mathrm{pH}$ and pressure were obtained on two consecutive nights from 6:00 p.m. to 6:30 a.m. in each subject. During each study, the subject remained recumbent, except to eat a standardized meal after $1 \mathrm{~h}$ of basal recording. A manometric assembly with seven recording lumens monitored: $(a)$ lower esophageal sphincter (LES) pressure via a sleeve device $6.5 \mathrm{~cm}$ in length, (b) esophageal-body motor activity, $(c)$ swallowing activity in the pharynx, and $(d)$ gastric pressure. An electrode $5 \mathrm{~cm}$ above the LES recorded esophageal $\mathrm{pH}$. Sleep was monitored by electroencephalogram. All subjects showed wide variations of basal LES pressure. GER was not related to low steady-state basal LES pressure, but rather occurred during transient 5-30 s episodes of inappropriate complete LES relaxation. The inappropriate LES relaxations were usually either spontaneous or immediately followed appropriate sphincter relaxation induced by swallowing. The majority of GER episodes occurred within the first $3 \mathrm{~h}$ after eating. During the night LES relaxation and GER occurred only during transient arousals from sleep or when the subjects were fully awake, but not during stable sleep. After GER the esophagus was generally cleared of refluxed acid by primary peristalsis and less frequently by secondary peristalsis. Nonperistaltic contractions were less effective than peristalsis for clearing acid from the esophagus. We conclude that in asympto-
\end{abstract}

A preliminary communication of this work was abstracted in 1978 (Gastroenterology. 74: 1119.) and was presented at the Meeting of the American Gastroenterological Association, Las Vegas, Nev., May 1978.

During this study Dr. Dent was the recipient of the Winthrop Travelling Fellowship of the Royal Australasian College of Physicians and Dr. Sekiguchi was supported by a study grant from the Japanese government.

Received for publication 3 January 1979 and in revised form 12 October 1979. matic recumbent subjects GER is related to transient inappropriate LES relaxations rather than to low steadystate basal LES pressure and also, that primary peristalsis is the major mechanism that clears the esophagus of refluxed material.

\section{INTRODUCTION}

Although nocturnal gastroesophageal $(\mathrm{GE})^{1}$ reflux is believed to play an important role in the production of reflux esophagitis, $(1,2)$ little data exists about the effect of sleep on lower esophageal sphincter function, GE reflux, and esophageal acid clearance. In the past, the technical limitations of conventional manometry have prevented accurate continuous recording of lower esophageal sphincter (LES) pressure (3). Consequently, analysis of LES antireflux function has relied on isolated samples of basal LES pressure (4), rather than measurement of the LES pressure occurring coincidently with GE reflux. Our aims in this study were to: $(a)$ determine the LES pressure coincident with the onset of GE reflux in healthy subjects, $(b)$ study the relationship of GE reflux to sleep, and (c) evaluate the mechanism of esophageal acid clearance.

\section{METHODS}

We did overnight esophageal manometric studies in 10 healthy volunteers, age 22-36 yr, who upon questioning had no history of esophageal symptoms and showed normal esophageal motor function on conventional esophageal manometry.

Each subject was studied for a 12-hr period on two consecutive nights. During each study, motor activity was recorded continuously from the stomach, LES, esophageal body, and pharynx. An intraluminal electrode measured esophageal $\mathrm{pH}$. On the second night, sleep stages were monitored with standard electroencephalographic (EEG) techniques $(5,6)$.

The manometric assembly was made from seven polyvinyl

\footnotetext{
${ }^{1}$ Abbreviations used in this paper: EEG, electroencephalographic; GE, gastroesophageal; LES, lower esophageal sphincter; LESR, LES relaxation(s); REM, rapid eye movement.
} 
catheters fused together longitudinally with tetrahydrofuran. Four catheters were $0.7 \mathrm{~mm}$ i.d. and $1.2 \mathrm{~mm}$ o.d., whereas the i.d. and o.d. of the other three catheters were 1.1 and $1.8 \mathrm{~mm}$, respectively. The bundle of catheters measured $4.5 \mathrm{~mm}$ in diameter. For LES pressure recording, we used a sleeve sensor (7), $6.5 \mathrm{~cm}$ in length and $3.3 \mathrm{~mm}$ in width. The sleeve was built on a silicon rubber assembly, $5.5 \mathrm{~mm}$ in diameter, that contained five silicon rubber catheters, each of $1.0 \mathrm{~mm}$ i.d. The lumina of the silicon assembly were joined to the distal ends of five of the polyvinyl catheters with stainless steel tubes, $6 \mathrm{~mm}$ in length, as stints. To permit infusion, the sleeve was connected at its proximal margin to the lumen of an underlying silicon rubber catheter. When infused, the sleeve functions as a variable resistor that gives an accurate continuous recording of LES pressure, despite oral-aboral motion of the $\operatorname{LES}(8,9)$ along the sleeve. With sphincter pullthrough methods, validation studies have shown that the sleeve sensor gives LES pressure values similar to those obtained by an infused catheter (7). In six other catheters, a side-hole recording orifice was made at the following levels: 1 and $3 \mathrm{~cm}$ distal to the distal end of the sleeve, at the proximal sleeve margin, and $7.5,15$, and $27 \mathrm{~cm}$ proximal to the sleeve. When this assembly was positioned with the sleeve straddling the LES, two catheters recorded gastric pressure, three catheters monitored motor activity in the esophageal body, and the most orad orifice signaled swallows from the pharynx. The recording orifices at the sleeve margins served to monitor sleeve position relative to the sphincter. An evaluation in five volunteers demonstrated that sudden displacement of the entire sleeve into the stomach by a rapid push-through, or from the stomach into the esophagus by a rapid pull-through, was detected on the tracing from the respective recording orifice at the proximal and distal sleeve margin, by the transient appearance of a high-pressure zone. Occasionally, a tracing pattern of LES pressure was recorded by an orifice at a sleeve margin when the sleeve was not positioned properly across the LES. In this circumstance, the sleeve position was adjusted. Each catheter was occluded with a stainless steel plug immediately distal to its lateral recording orifice. For pressure recording, each catheter was filled with water and the sleeve and two gastric catheters, $1.1 \mathrm{~mm}$ i.d., were infused with bubble-free water at $0.5 \mathrm{ml} / \mathrm{min}$ by a hydraulic-capillary pump with minimal compliance (10). Pressure tracings were recorded on an eight-channel Beckman polygraph (Beckman Instruments, Inc., Fullerton, Calif.).

The subjects fasted $5 \mathrm{~h}$ before each study. After the manometric assembly was passed through the nose, the LES was located by a station pull-through and the $6.5-\mathrm{cm}$ sleeve positioned so that it straddled the LES. A Beckman pH electrode was passed through the same nostril as the manometric assembly, advanced into the stomach to identify an acid $\mathrm{pH}$, and then positioned in the esophagus $5 \mathrm{~cm}$ proximal to the LES. The manometric assembly and $\mathrm{pH}$ electrode were taped securely at the nose and their position repeatedly checked throughout each study for slippage. For both study nights on each subject, 11 cutaneous electrodes were positioned on the scalp and face. The first study night was allowed for adaptation. On the second study night, sleep and awake states were monitored by electroencephalogram, electrooculogram, and chin electromyogram recording with an eight-channel Grass EEG polygraph (Grass Instrument Co., Quincy, Mass.). During recording, the EEG polygraph ran at a paper speed of $30 \mathrm{~mm} / \mathrm{s}$, whereas the Beckman polygraph ran at $1 \mathrm{~mm} / \mathrm{s}$. The two recordings were synchronized by recording one of the esophageal body pressure tracings on both polygraphs. Additionally, a manual event marker was used to signal the page numbers of the EEG tracing on the manometric record. The subject slept in a quiet, darkened room adjacent to a room housing the monitoring equipment.
Esophageal manometric and $\mathrm{pH}$ recording were begun about 6:00 p.m. in the evening. During recording the subject remained recumbent on a bed, lying either on his or her back or side. Although frequently notated, subject position was not continuously monitored. While awake, the subjects generally read or watched television. No smoking, alcohol, or coffee was permitted. After $1 \mathrm{~h}$ of recording the subject sat to eat a standardized, balanced 800 -calorie meal that contained $40 \mathrm{~g}$ carbohydrate, $40 \mathrm{~g}$ protein, and $53 \mathrm{~g}$ fat. After completion of the meal in about $30 \mathrm{~min}$, the subject resumed the recumbent position and recording was continued for another $11 \mathrm{~h}$, until about 6:30 a.m. On the second study night, the EEG recording was begun about 11:00 p.m., when the subject felt ready to sleep, and continued throughout the night. During each study, an investigator monitored the subject and recording equipment. At the termination of each study the manometric and $\mathrm{pH}$ channels were checked for drift and calibration.

For purposes of data analysis, basal LES pressure on each tracing was measured for 10 -min periods by a planimetric method. By planimetry we subtracted end-expiratory gastric pressure from end-expiratory LES pressure to provide a mean LES pressure value for each 10-min period of tracing. Before planimetry, physiologic variations in LES pressure associated with esophageal peristalsis and phase III interdigestive gastric motor activity were edited. Measurements were done in duplicate and the results averaged. The variation between measurements was $<5 \%$. Basal LES pressure during the 1 -min interval immediately before each episode of GE reflux was scored as the visually determined mean expiratory sphincter pressure, referencing end-expiratory gastric pressure as zero. To obtain an assessment of the minute-to-minute variability in LES pressure, mean basal LES pressure was measured for each minute interval during the hour before and after eating on the first night studies. All motor activity in the esophageal body was categorized as peristaltic or nonperistaltic activity. Esophageal peristalsis was judged primary when immediately preceeded by a swallow recorded by the pharyngeal sensor. Primary peristalsis was considered as "failed" when swallowing either did not elicit esophageal peristalsis, or the stripping wave did not traverse the entire esophagus. Episodes of acid GE reflux were scored when esophageal $\mathrm{pH}$ fell below pH 4.0 for $5 \mathrm{~s}$ or longer. Esophageal-body motor activity associated with esophageal clearance was also scored, as well as the time for esophageal $\mathrm{pH}$ to return to $\mathrm{pH} 2.0$, 3.0, and 4.0. The EEG tracings were analyzed in 20-s epochs for stages of sleep and arousals according to accepted criteria $(5,6)$. When an esophageal motor event was recorded during sleep the trace was analyzed for the occurrence of a movement arousal, as defined by Rechtschaffen and Kales (5). When such an arousal accompanied the onset of an esophageal motor event, that event was not scored as having occurred during sleep, but during an arousal. Tests for statistical analysis were performed by the paired or unpaired Student's $t$ test.

\section{RESULTS}

Basal LES pressure. Considerable variation in the values and pattern of basal LES pressure was observed in each of the 10 study subjects. Substantial minuteto-minute variations in LES pressure were observed in each subject during some intervals of their tracings, whereas during other intervals LES pressure was stable. For the preprandial hour the standard deviations of minute-to-minute basal LES pressure ranged from 4 to $9 \mathrm{~mm} \mathrm{Hg}$ with a mean value of $6 \mathrm{~mm} \mathrm{Hg}$. Comparable 
(A)
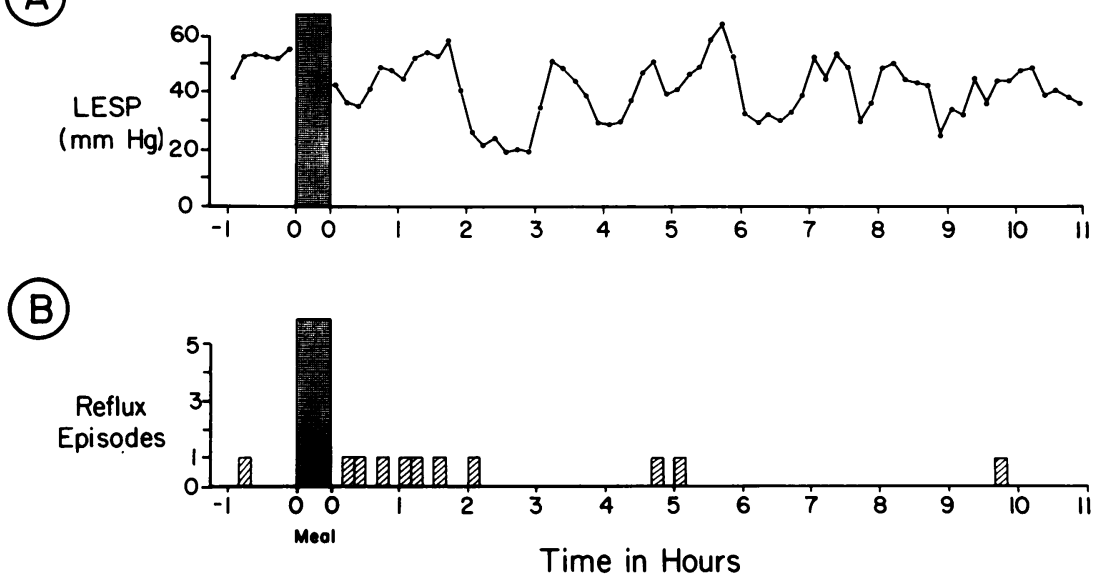

FIGURE 1 Overnight monitoring of basal LES pressure (LESP) and GE reflux in a healthy volunteer subject. (A) Mean LESP is calculated for 10-min intervals (B) Number of reflux episodes shown for each 10-min interval. The shaded bar indicates when the patient sat up to eat. Resting LESP is seen to vary widely during the 12 -h period of recording. The episodes of GE reflux were not associated with intervals of low basal LESP.

variability was shown for the 1-h interval after eating. Analysis of the mean basal LES pressure values for 10-min epochs during individual study nights (Fig. 1A) showed a wide range of 10 -min LES pressure values for both study nights in each subject. The overall mean as well as lowest and highest mean 10-minute LES pressure values for the 20 study nights are shown in Fig. 2. For the 20 studies the mean of lowest 10-min LES pressure values was $10 \pm 5 \mathrm{~mm} \mathrm{Hg} \mathrm{SD}$, whereas the highest values averaged $55 \pm 10 \mathrm{~mm} \mathrm{Hg}$. The composit temporal pattern of LES pressure obtained by averaging LES pressure measurements for 10-min epochs in all 10 subjects ( 20 studies) is shown in Fig. 3A. Significant decrease in LES pressure occurred after the meal and basal LES pressure tended to rise during the middle of the night.

GE reflux. A total of 272 episodes of acid GE reflux occurred on the 20 study nights. In 9 of the 10 subjects the number of reflux episodes ranged from 1 to 24 on their first study night and from 0 to 23 on their second study night. The 10th subject (T.W.) exhibited 52 reflux episodes on his first study night and 36 episodes on the second study night. Subsequently, this subject admitted to having mild heartburn about once a week. Although moderate variation existed in the number of reflux episodes between individuals (Fig. 4), close correlation was found for the number of acid reflux episodes between studies in the same individual $(r=0.9$,

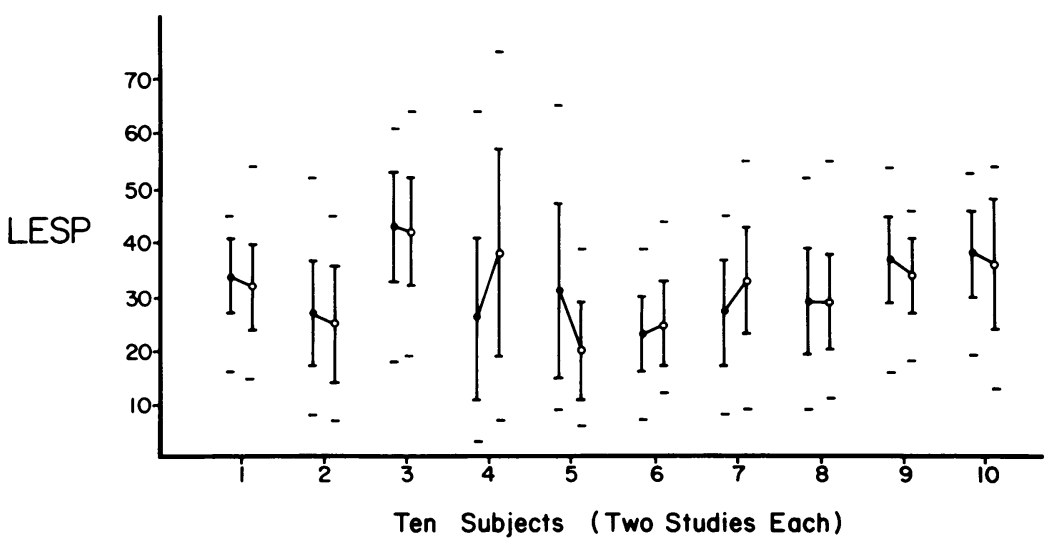

FIGURE 2 Mean 10-min basal LES pressure (LESP) values obtained from two 12-h studies in each of 10 subjects. The solid circles indicate the mean 10 -min LESP values on the first study and the open circles indicate mean 10-min LESP on the second study. The vertical lines show \pm 1 SD. The unconnected, horizontal bars indicate the high and low LESP values for each study. 


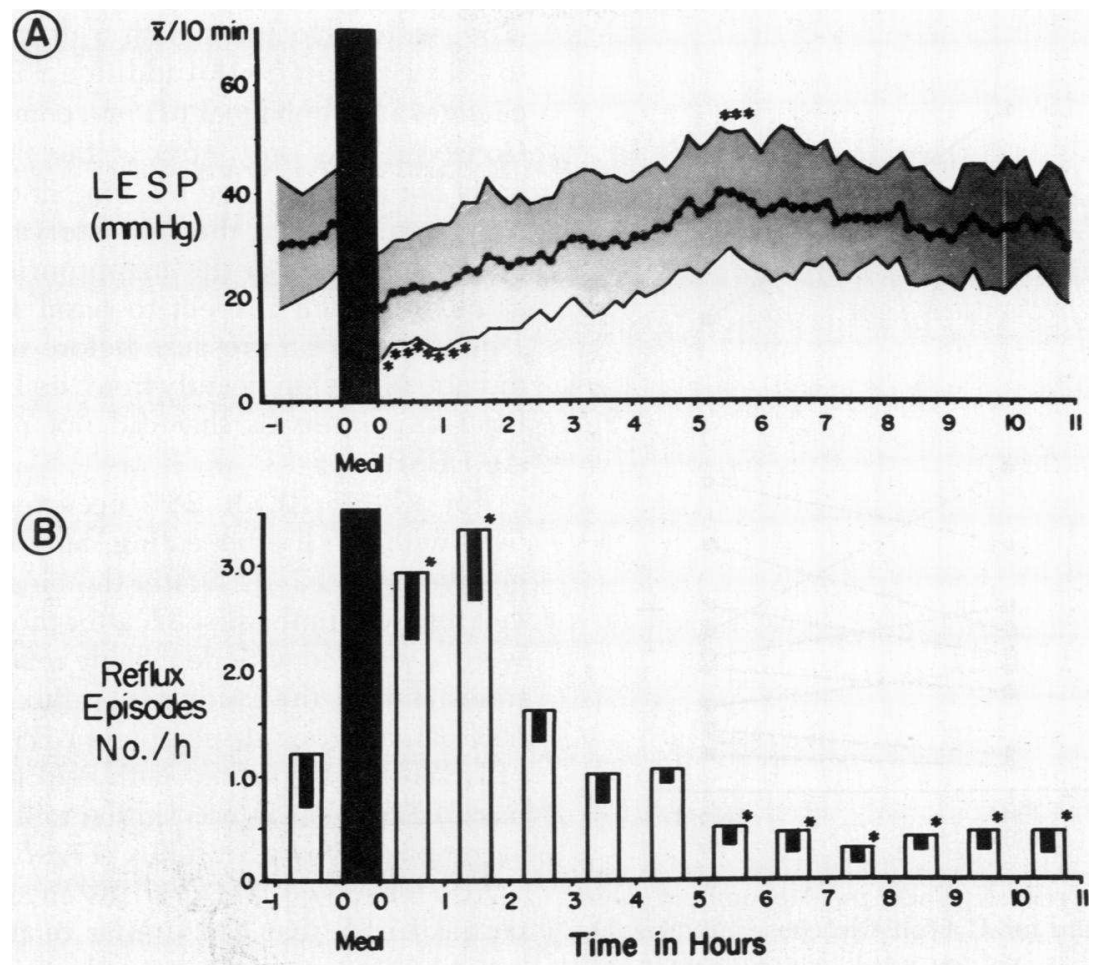

FIGURE 3 Graph showing LES pressure (LESP) and number of reflux episodes in 10 volunteer subjects, each studied for $12 \mathrm{~h}$ on two consecutive nights. An asterisk indicates values that differed significantly from the pre-prandial values. (A) Resting LESP scored as mean 10-min values. The black dots and heavy black line are mean values and the area shaded light gray is $\pm 1 \mathrm{SD}$. After the meal LESP decreased significantly for $80 \mathrm{~min}$, and $6 \mathrm{~h}$ after the meal, at about 3:30 a.m., LESP was significantly higher than the control values. (B) Episodes of reflux are plotted as number per hour. The frequency of reflux increased significantly during the first $2 \mathrm{~h}$ after eating. During the night, from 12:30 to 6:30 a.m., 5-11 h after eating, the frequency of reflux was significantly lower than for the preprandial control period.

$P<0.01)$. The majority of the reflux episodes occurred within a few hours after the meal, but about $20 \%$ occurred after midnight (Fig. 3B). Excluding subject T.W., the hourly rate of reflux episodes were as follows: 0.7 $\pm 0.7 \mathrm{SD} / \mathrm{h}$ before eating, $2.2 \pm 1.4 / \mathrm{h} 0-3 \mathrm{~h}$ after the meal, and $0.4 \pm 0.3 / \mathrm{h} 3-11 \mathrm{~h}$ after the meal. The reflux rate for the entire 12 -h period was $0.9 \pm 0.6 / \mathrm{h}$. Esophageal $\mathrm{pH}$ was $<4.0$ for $1.3 \pm 2.1 \%$ of the preprandial hour, $8.4 \pm 4.3 \%$ for the $3 \mathrm{~h}$ after eating, and $2.4 \pm 3.3 \%$ from $3-11 \mathrm{~h}$ after eating.

The majority (82\%) of episodes of acid GE reflux were associated with an identifiable common cavity phenomenon (11), manifested as an abrupt rise of 5-10 $\mathrm{mm} \mathrm{Hg}$ in esophageal-body pressure so that intraesophageal pressure transiently equalled gastric pressure. About $70 \%$ of these common cavity phenomena were registered by the recording orifices in the middle and distal esophagus, whereas the remainder were recorded only in the distal esophagus. In some instances, generally within the first $20 \mathrm{~min}$ after the meal, common cavity phenomena occurred without any change in esophageal pH. More commonly transient, modest drops of esophageal $\mathrm{pH}$ occurred that did not reach a $\mathrm{pH}$ of 4 , but were associated with a common cavity phenomenon. By our criteria, these events were not scored as acid GE reflux, albeit they probably were reflux events.

GE reflux and LES pressure. The relationship of acid reflux episodes to mean LES pressure for 10-min epochs during which the reflux episode occurred was variable in individual subjects (Fig. 1B). For pooled data from all subjects $60 \%$ of the reflux episodes occurred during 10-min intervals when mean LES pressure was $20 \mathrm{~mm} \mathrm{Hg}$ or greater (Fig. 5A). Probably even more significant is the data demonstrating the relationship of GE reflux episodes to the basal LES pressure recorded during the 1-min interval immediately preceding reflux (Fig. 5B). This data also showed no correlation between GE reflux and low basal LES pressure.

Rather than occurring during intervals of persistently low basal LES pressure or when abdominal pressure transients overcame LES tone, 98\% of GE reflux episodes (266) were associated with transient inappropri- 


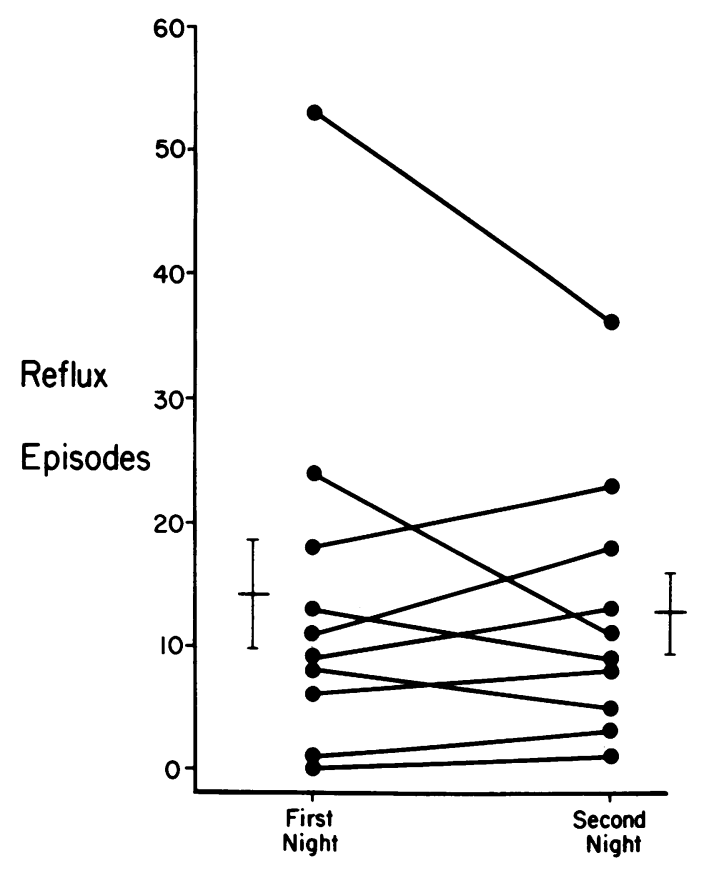

FIGURE 4 Number of reflux episodes in 10 recumbent volunteer subjects monitored for $12 \mathrm{~h}$ on two consecutive nights. The short horizontal bars and vertical lines indicate mean \pm 1 $\mathrm{SD}$. Although moderate variation in the number of reflux episodes occurred between subjects, individual subjects tended to have a similar number of reflux episodes on their two studies. Nine of the subjects had 24 or less reflux episodes per study. The 10th subject had a substantially higher number of reflux episodes and later admitted experiencing heartburn about once a week.

ate LES relaxation (LESR) to intragastric pressure. These LESR were inappropriate because they did not occur during a normal primary or secondary peristaltic sequence. LESR associated with acid reflux lasted from 5 to $30 \mathrm{~s}$. Only four of these LESR were accompanied by transient increases in intragastric pressure caused by straining or body movement.

Several different types of LESR were associated with GE reflux. About one-third of the LESR (34\%) occurred spontaneously without any coexisting motor activity in the esophageal body (Fig. 6). Another third of the inappropriate LESR (33\%) occurred after one or more peristaltic sequences, within a few seconds after the sphincter had recovered from its appropriate physiologic relaxation in response to a normal, swallow-induced peristaltic sequence (Fig. 7). $13 \%$ of the LESR associated with reflux occurred during an incomplete peristaltic sequence (Fig. 8). Spontaneous nonperistaltic contraction waves accompanied 9\% of the LESR. Miscellaneous types of LESR, including those associated with multiple swallows, nonpropagated pharyngeal contractions, and failed secondary peristalsis, accounted for $11 \%$.

Of 445 inappropriate complete LESR, about $60 \%$
(266) were associated with a drop of esophageal $\mathrm{pH}$ to 4.0 for at least $5 \mathrm{~s}$. An additional $25 \%$ exhibited small changes in esophageal $\mathrm{pH}$ or a common cavity or both. Consequently, only $15 \%$ of the inappropriate LESR were not accompanied by some finding suggesting GE reflux. Analysis of the 1-h intervals before and after eating showed that the inappropriate LESR occurred at random with respect to basal LES pressure. The 1-min basal LES pressure before inappropriate LESR did not differ significantly from the LES pressure values for 1-min intervals that did not precede inappropriate LESR.

For all 445 LESR, $28 \%$ occurred before the meal, $54 \%$ within $3 \mathrm{~h}$ after eating, and $18 \%$ in the interdigestive period $3-11 \mathrm{~h}$ after the meal. Of interest is the fact that within the first $3 \mathrm{~h}$ after the meal 93\% of LESR were associated with detectable reflux, whereas at other times during the study GE reflux accompanied only $69 \%$ of inappropriate complete LESR. The relationship of LESR not associated with acid reflux to antecedent basal LES pressure was similar to that shown for LESR accompanied by acid reflux (Fig. 5B).

Also observed were 60 instances of inappropriate partial LESR that had similar relationships to esophageal body motor activity as the complete form. None of these partial LESR were accompanied by evidence suggesting GE reflux.

Esophageal clearance. For the majority of reflux episodes esophageal $\mathrm{pH}$ returned to 4 in $<2-3 \mathrm{~min}$ (Fig. 9). Esophageal $\mathrm{pH}$ remained below 4 for more than $5 \mathrm{~min}$ in $<12 \%$ of the reflux episodes. Only $1 \%$ of GE reflux events were associated with an esophageal $\mathrm{pH}<4$ that persisted for more than 20 -min.

The major mechanism of esophageal acid clearance was multiple sequences of esophageal peristalsis (Fig. 8). The major type of esophageal-body motor activity after reflux was swallow-induced peristalsis (Table I), which accounted for $67 \%$ of all esophageal-body motor activity while the $\mathrm{pH}$ was $<4$. Further, the initial esophageal-body motor event after acid GE reflux was primary peristalsis in $54 \%$ of reflux episodes (Fig. 6), secondary peristalsis in $27 \%$, and spontaneous, nonperistaltic contractions in $19 \%$ (Fig. 8).

In $80 \%$ of reflux episodes an esophageal-body motor event occurred within $20 \mathrm{~s}$ of reflux and in $93 \%$ an esophageal-body contraction occurred within $60 \mathrm{~s}$. The frequency of different types of esophageal-body motor activity after reflux compared to periods when esophageal $\mathrm{pH}$ was above 4.0 is shown in Table II. Although GE reflux was associated with a significant increase in the frequency of secondary peristalsis, the most common motor event remained primary peristalsis. Esophageal $\mathrm{pH}<4.0$ was not associated with a significant increase in the rate of primary peristalsis, but a trend existed when the $\mathrm{pH}$ was $\leq 2.0(P=0.1)$. A pH $\leq 2.0$ was also associated with an increase in the rate of 
simultaneous esophageal contractions, but the change was not statistically significant.

Often each peristaltic sequence was associated with a step up of esophageal $\mathrm{pH}$ until the pre-reflux $\mathrm{pH}$ of 5-6 was restored (Fig. 8). In some episodes the initial peristaltic sequence or sequences caused little or no change in esophageal $\mathrm{pH}$, whereas subsequent peristalsis caused the step-like $\mathrm{pH}$ increases. Between peristaltic sequences the $\mathrm{pH}$ tended to climb slowly at about $1 \mathrm{pH}$ U/5-10 min. Consequently, when multiple sequences of esophageal peristalsis did not occur after acid reflux, esophageal clearance was prolonged (Fig. 7). Incomplete peristaltic sequences and spontaneous, nonperistaltic esophageal contractions were significantly less effective in clearing acid than either primary or secondary peristalsis (Table III).

Sleep analysis. During the night the subjects dem-
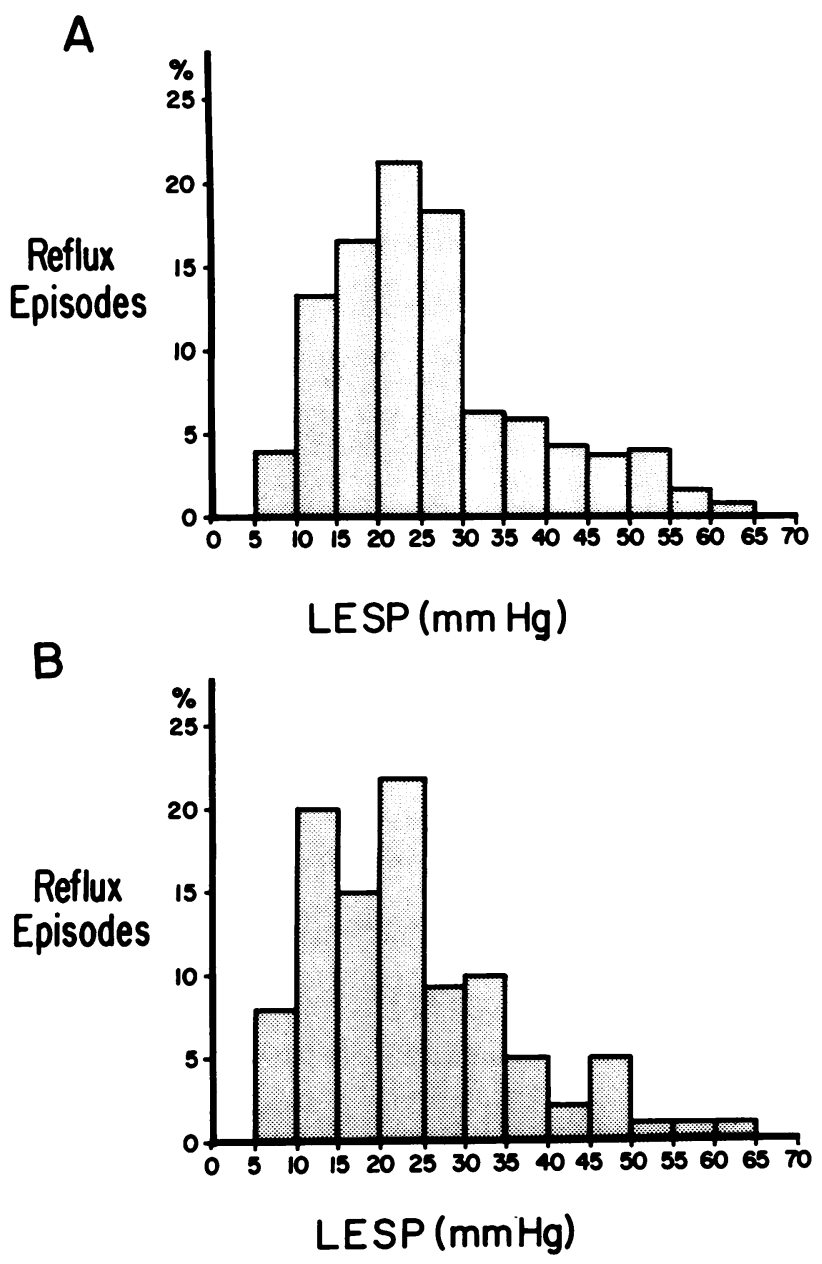

FIGURE 5 Relationship between resting LES pressure (LESP) and GE reflux. The frequency distribution is shown for reflux episodes vs.: (A) mean resting LESP for the 10-min interval during which a reflux episode occurred, or (B) mean resting LESP for the minute preceeding reflux.

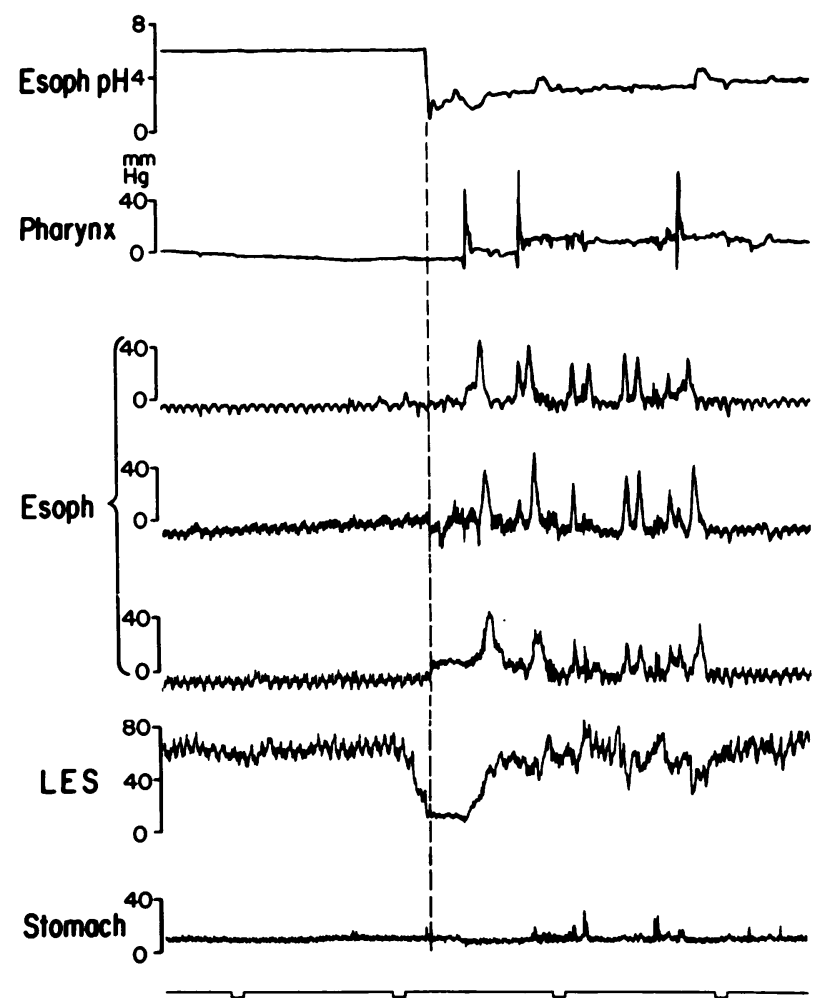

\section{Time in Minutes}

FIGURE 6 GE reflux associated with spontaneous LESR. Onset of esophageal reflux is indicated by the vertical dashed line. Before reflux, resting LES pressure was stable at about $50 \mathrm{~mm} \mathrm{Hg}$ above intragastric pressure. The abrupt occurrence of acid reflux into the esophagus was coincident with an inappropriate spontaneous relaxation of LES tone. Reflux occurred only when the LES relaxed completely to gastric pressure. The acid reflux was accompanied by a common cavity phenomenon, seen as a sudden step-up of intraluminal pressure in the distal esophagus to gastric pressure. After reflux, peristaltic sequences began to clear acid from the esophagus. On this segment of the tracing, each of three peristaltic sequences, elicited by swallows shown on the pharyngeal recording, was associated with a step-up of esophageal pH. Spontaneous, simultaneous contractions occurring between swallows did not raise esophageal $\mathrm{pH}$.

onstrated periods of sleep lasting 10-90 min interrupted by brief arousals. Early in the night the subjects tended to pass through sleep stages I-IV and then undergo an arousal. Later in the night the sleep stages tended to be limited to rapid eye movement (REM) and stages I and II (Fig. 10). Many variations, however, occurred in the sleep stages.

Generally, swallowing and primary peristalsis occurred when the subject was fully awake and during arousal periods from sleep, often as clusters of 5-10 swallows. During stable sleep, primary or secondary peristalsis occurred infrequently. Nonperistaltic contractions were somewhat more frequent (Fig. 10). Most 


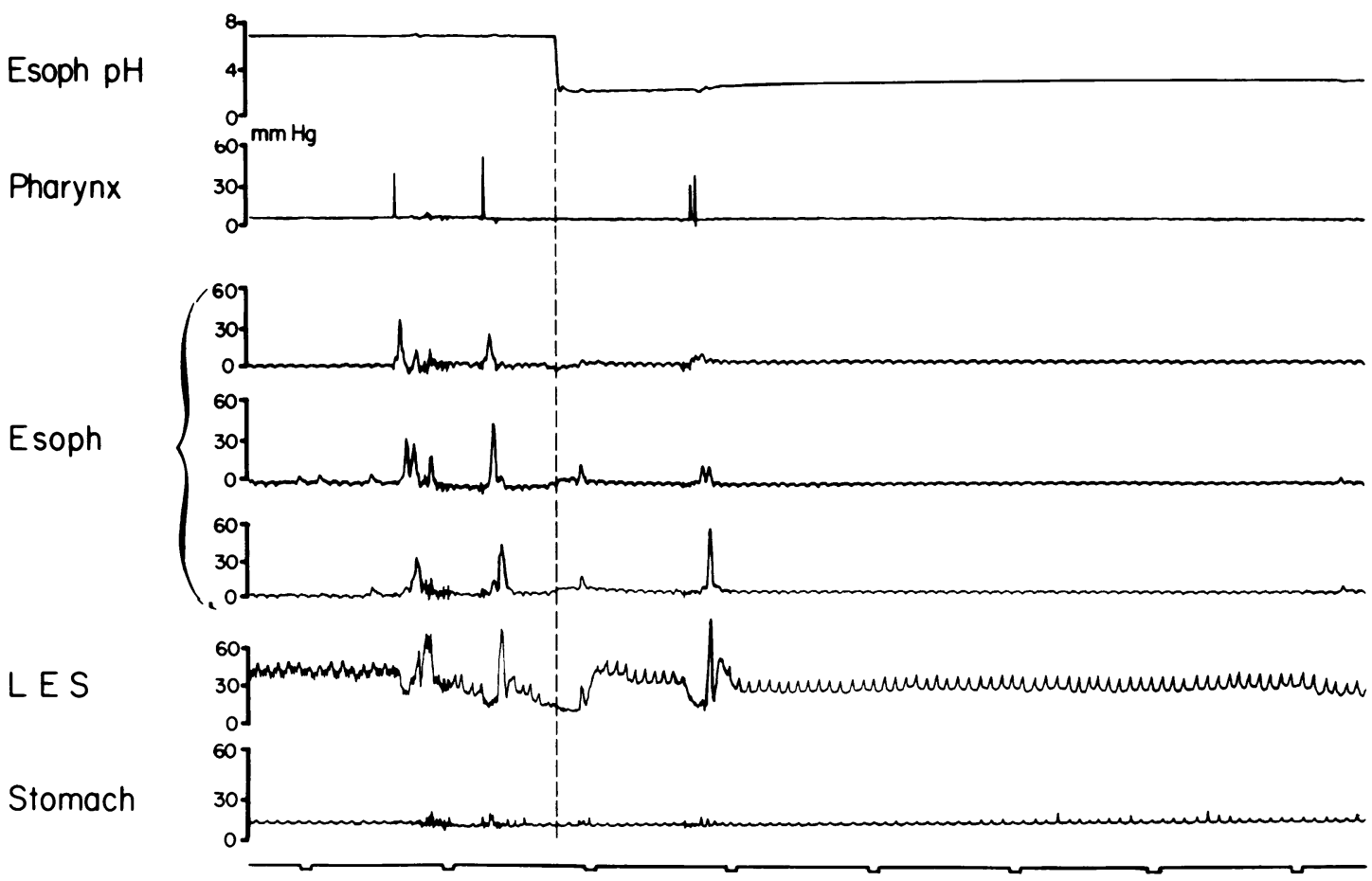

\section{Time in Minutes}

FIGURE 7 GE reflux after swallowing-induced peristalsis. Onset of reflux is indicated by the dashed line. Before reflux, the LES relaxed appropriately after two swallows, which occurred during an arousal from sleep. After the second peristaltic sequence, LES pressure returned to its initial resting value, but then collapsed without any identifiable precipitating motor event. During this inappropriate LESR, acid reflux occurred, accompanied by a common cavity phenomenon. Immediately after reflux, a feeble, nonperistaltic, simultaneous contraction occurred in the mid and distal esophagus, followed 1 min later by a single primary peristaltic sequence, triggered by two closely spaced swallows, which caused only a slight increase in esophageal $\mathrm{pH}$. The subject then fell back asleep. No further swallows or esophageal motor activity occurred until 20 min later, when the subject had another arousal. During this $20 \mathrm{~min}$ sleep interval the esophageal $\mathrm{pH}$ climbed very slowly, but remained $<4.0$.

of the esophageal-body motor events accompanying sleep occurred during REM sleep (Table IV).

During the night, episodes of inappropriate LESR and acid GE reflux developed only during arousals or more prolonged periods of wakefulness, never during actual sleep. In most instances, the esophagus was rapidly cleared of refluxed acid by primary or secondary peristalsis or both (Figs. 6 and 8). In a few instances, the subject drifted back into sleep before esophageal clearance was complete. In this circumstance, esophageal clearance was prolonged for 20-30 min because peristalsis seldom developed during sleep (Fig. 7).

\section{DISCUSSION}

The results of this study indicate that in normal recumbent subjects: $(a)$ resting basal LES pressure shows considerable temporal variation during a $12 \mathrm{~h}$ period; (b) GE reflux occurs commonly within several hours after a meal, and less frequently during the night; $(c)$ episodes of GE reflux are not related to low basal LES pressure, but rather to inappropriate, complete relaxation of LES tone; $(d)$ peristalsis is the major determinant of acid clearance from the esophageal body; (e) during sleep periods swallowing occurs mainly during intermittent arousals; and $(f)$ inappropriate LESR and GE reflux never developed during true sleep, only during periods of full wakefulness or sleep arousals.

In the past, technical limitations have prevented reliable prolonged monitoring of LES pressure. Difficulty exists in maintaining an infused catheter orifice at a fixed position within the LES (3) and the sphincter moves relative to the recording catheter during respiration and peristalsis $(8,9)$. Probably for this reason, many 


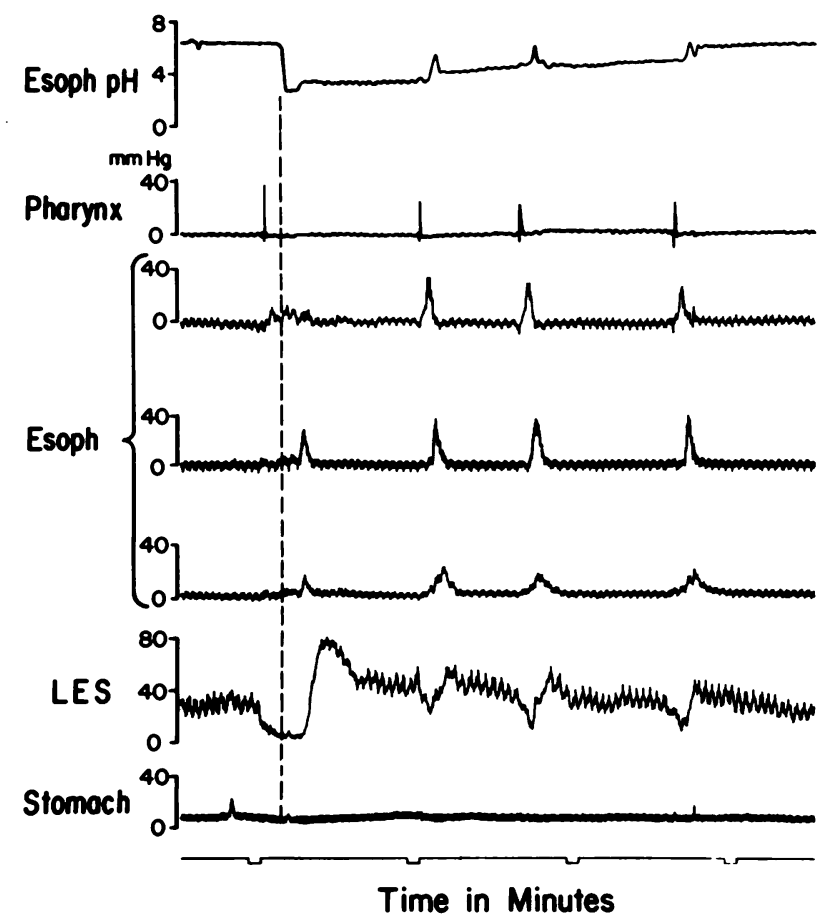

FIGURE 8 GE reflux associated with an incomplete primary peristaltic sequence. The dashed line indicates the onset of esophageal reflux. Before reflux, swallowing induced LESR, but the peristaltic sequence broke before reaching the mid esophagus. Reflux occurred during this unguarded moment of LESR, when peristalsis was absent in the distal esophagus. About $5 \mathrm{~s}$ after reflux, a spontaneous, simultaneous contraction wave occurred in the distal half of the esophagus. During the next $3 \mathrm{~min}$ three swallow-induced peristaltic sequences caused step-like elevations of esophageal $\mathrm{pH}$ and returned the pH to its pre-reflux value. workers have tried to correlate samples of basal LES pressure with symptoms of GE reflux. The recent $d \epsilon-$ velopment of a sleeve sensor, (7) however, now allows reliable continuous recording of LES pressure in humans, despite axial sphincter movement along the sensor. This technical advance in LES pressure monitoring made the present study feasible.

Although other workers have reported temporal variability in LES pressure, (4) our continuous tracings of basal LES pressure demonstrated considerably more variation than we anticipated. This basal LES pressure variation occurred from minute to minute and also over longer intervals as shown by the analysis of mean 10-min LES pressure values. Such variations in LES pressure raise doubt as to the significance of isolated samples of LES pressure. Variability of LES tone was seen during the 1-h control period, after eating, and during the night. Resting LES pressure decreased significantly for $2 \mathrm{~h}$ after eating, probably caused by fat in the meal, and was highest during the middle of the night.

Episodes of acid GE reflux occurred in each of the 10 subjects, and on all except one of the 20 studies. For a given subject the reflux episodes were similar in number for the two study nights, but variation occurred between subjects. A common cavity phenomenon (11) usually accompanied episodes of GE reflux. Common cavity phenomena were also observed without drops in $\mathrm{pH}$, especially soon after the meal, suggesting reflux of $\mathrm{pH}$ neutral material. Additionally, we observed small drops of esophageal $\mathrm{pH}$, generally associated with common cavity phenomena, that probably represented reflux of either small amounts of acid, gastric juice with a $\mathrm{pH}>4$, or gas. Our finding that

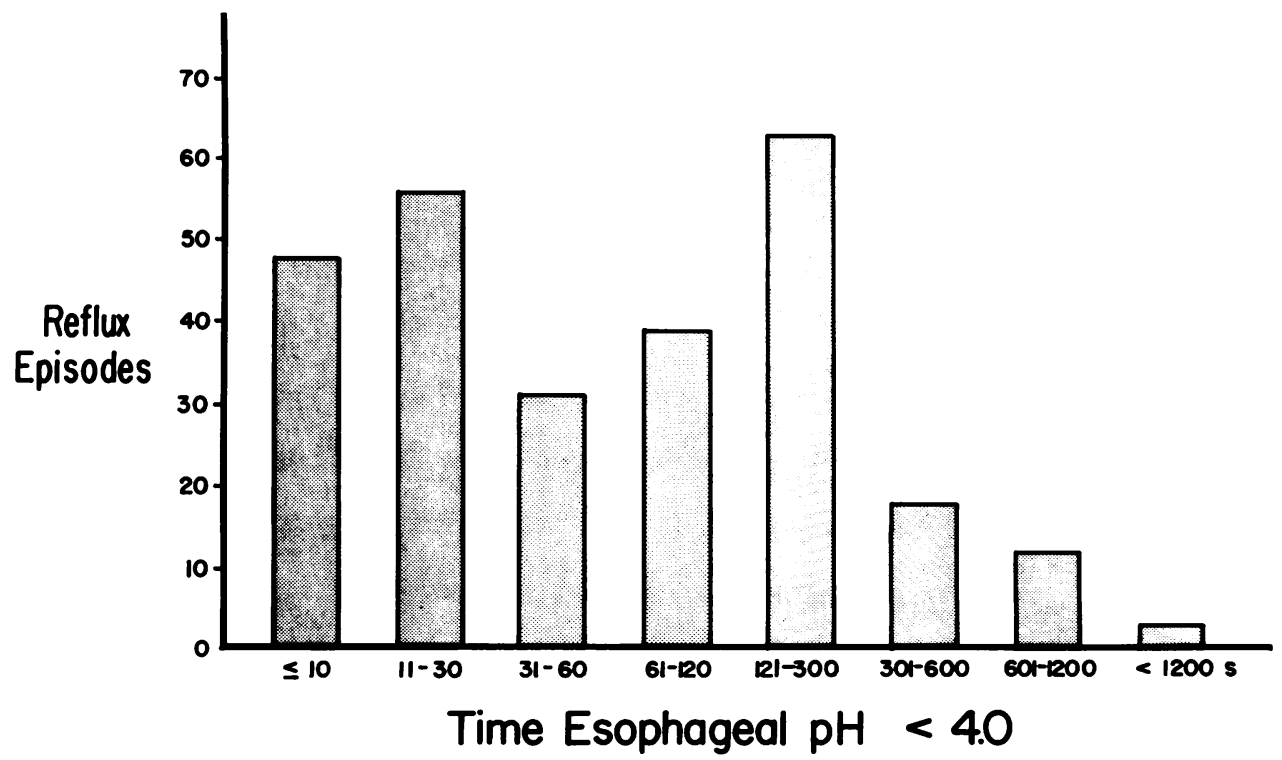

FIGURE 9 Frequency distribution of the duration esophageal pH remained $<4.0$ after 266 episodes of gastroesophageal acid reflux. 
TABLE I

Esophageal-Body Motor Activity at Esophageal $p H<4$ after GE Reflux

\begin{tabular}{lrrr}
\hline & $\begin{array}{c}\text { Number } \\
\text { of events }\end{array}$ & \multicolumn{2}{c}{ Percentage of total } \\
\hline & & \multicolumn{2}{c}{$\%$} \\
Primary peristalsis & 476 & 67 & \\
Failed primary & 37 & 5 & 72 \\
Secondary peristalsis & 108 & 15 & 15 \\
Spontaneous nonperistaltic & 90 & 13 & 13 \\
Totals & 711 & 100 & 100 \\
\hline
\end{tabular}

multiple episodes of GE reflux occur in recumbent, asymptomatic subjects with normal esophageal function serves to reinforce the findings of other workers (12-15).

An important consideration is that the presence of the sleeve sensor across the LES may have prompted GE reflux in our volunteer subjects. Earlier studies suggest that an indwelling nasogastric tube promotes GE reflux in normal individuals lying supine $(16,17)$. In a recent study, however, Fisher et al. (18), with a scintiscan method, conclude that a tube across the LES does not cause increased GE reflux. Further, the pre- and post-prandial incidence and duration of GE reflux in our study volunteers was similar to the findings from some other studies in which esophageal $\mathrm{pH}$ was monitored without a tube across the LES in recumbent normal subjects $(12,13,19)$. For these reasons, we believe that the presence of the sleeve catheter assembly straddling the LES did not act as a major factor in eliciting GE reflux in normal subjects. This conclusion is strengthened by the observation that GE reflux occurred only during transient inappropriate LESR.

Contrary to current belief, our measurements suggest that episodes of acid GE reflux may not correlate with low resting LES pressure. Perhaps this finding should not be too surprising: $(a)$ atropine, which lowers LES pressure in normal subjects, does not increase the fre- quency of reflux $(20,21) ;(b)$ considerable overlap of LES pressure exists between sample measurements obtained in control subjects and patients with reflux esophagitis (2); and (c) bethanechol-induced increases in LES pressure to about $30 \mathrm{~mm} \mathrm{Hg}$ in patients with free $\mathrm{GE}$ reflux reduces, but does not abolish the reflux (22). In this study even a minimal basal LES pressure of 5-10 mm Hg was sufficient to prevent reflux in recumbent volunteer subjects.

If $\mathrm{GE}$ reflux in recumbent healthy subjects is not related to low basal LES pressure, by what mechanism then do reflux episodes occur? In the subjects studied, reflux episodes were nearly always associated with random transient episodes of inappropriate complete LESR, that lasted 5-30 s. Thus, GE reflux in normal subjects is closely related to transient reduction of LES pressure, albeit not to low basal LES pressure. Preliminary work suggests a similar association between inappropriate LESR and GE reflux exists in some patients with reflux esophagitis (unpublished observations). During the "unguarded moments" of inappropriate LESR the distal esophageal body was not sealed by a peristaltic circular contraction. Consequently, the conditions were favorable for GE reflux. Reflux, however, did not invariably develop during all inappropriate complete LESR, particularly when these LESR occurred more than $3 \mathrm{~h}$ after eating. Thus, the probability for reflux may be partially determined by the volume of gastric contents, and perhaps by subject position. GE reflux was never observed during incomplete LESR, and abdominal pressure increases such as caused by straining or movement accompanied fewer than $5 \%$ of the GE reflux episodes that occurred during transient LESR.

The stimuli responsible for the transient inappropriate LESR observed in this study are not understood at present. An unguarded moment of LES relaxation accompanying an incomplete peristaltic sequence or a nonperistaltic contraction seems relatively straightforward (23). The transient LESR, however, that occur

TABLE II

Frequency of Different Types of Esophageal-Body Motor Activity in Nine Awake Volunteers between and during Episodes of GE Acid Reflux*

\begin{tabular}{cccccc}
\hline $\begin{array}{c}\text { Esophageal } \\
\text { pH }\end{array}$ & $\begin{array}{c}\text { Swallows } \\
\text { per hour }\end{array}$ & $\begin{array}{c}\text { Normal primary } \\
\text { peristalsis }\end{array}$ & $\begin{array}{c}\text { Failed primary } \\
\text { peristalsis }\end{array}$ & $\begin{array}{c}\text { Normal secondary } \\
\text { peristalsis }\end{array}$ & $\begin{array}{c}\text { Simultaneous } \\
\text { contractions }\end{array}$ \\
\hline$>4.0$ & $52 \pm 7$ & $47 \pm 5$ & $5 \pm 2$ & $2 \pm 1$ & $12 \pm 2$ \\
$\leq 4.0$ & $39 \pm 9$ & $36 \pm 8$ & $3 \pm 1$ & $9 \pm 2 \S$ & $10 \pm 3$ \\
$\leq 3.0$ & $58 \pm 13$ & $54 \pm 12$ & $4 \pm 2$ & $27 \pm 13 \S$ & $16 \pm 8$ \\
$\leq 2.0$ & $133 \pm 61 \ddagger$ & $131 \pm 60 \ddagger$ & $2 \pm 2$ & $116 \pm 47 \S$ & $26 \pm 20$ \\
\hline
\end{tabular}

$* P=0.1$.

$\$$ Values are mean \pm 1 SE events per hour.

$\S P<0.05$. 
TABLE III

Changes in Esophageal pH Associated with Different Esophageal Body Motor Events Occurring after 272 Episodes of GE Acid Reflux in 10 Volunteer

Subjects during 20 Study Sessions*

\begin{tabular}{ccccc}
\hline Type event & $\begin{array}{c}\text { Primary } \\
\text { peristalsis }\end{array}$ & $\begin{array}{c}\text { Secondary } \\
\text { peristalsis }\end{array}$ & $\begin{array}{c}\text { Failed primary } \\
\text { peristalsis }\end{array}$ & $\begin{array}{c}\text { Nonperistaltic } \\
\text { spontaneous } \\
\text { contractions }\end{array}$ \\
\hline First event after reflux & $1.12 \pm 0.8$ & $1.13 \pm 1.0$ & $\Delta p h$ & $0.5 \pm 0.4 \ddagger$ \\
All events at $\mathrm{pH}<4.0$ & $0.73 \pm 0.7$ & $0.86 \pm 1.0$ & $0.3 \pm 0.4 \ddagger$ & $0.59 \pm 0.7 \ddagger$ \\
\hline
\end{tabular}

* All values given as mean $\pm 1 \mathrm{SD}$.

$\ddagger$ Indicates values significantly less than those for primary and secondary peristalsis $(P<0.05)$.
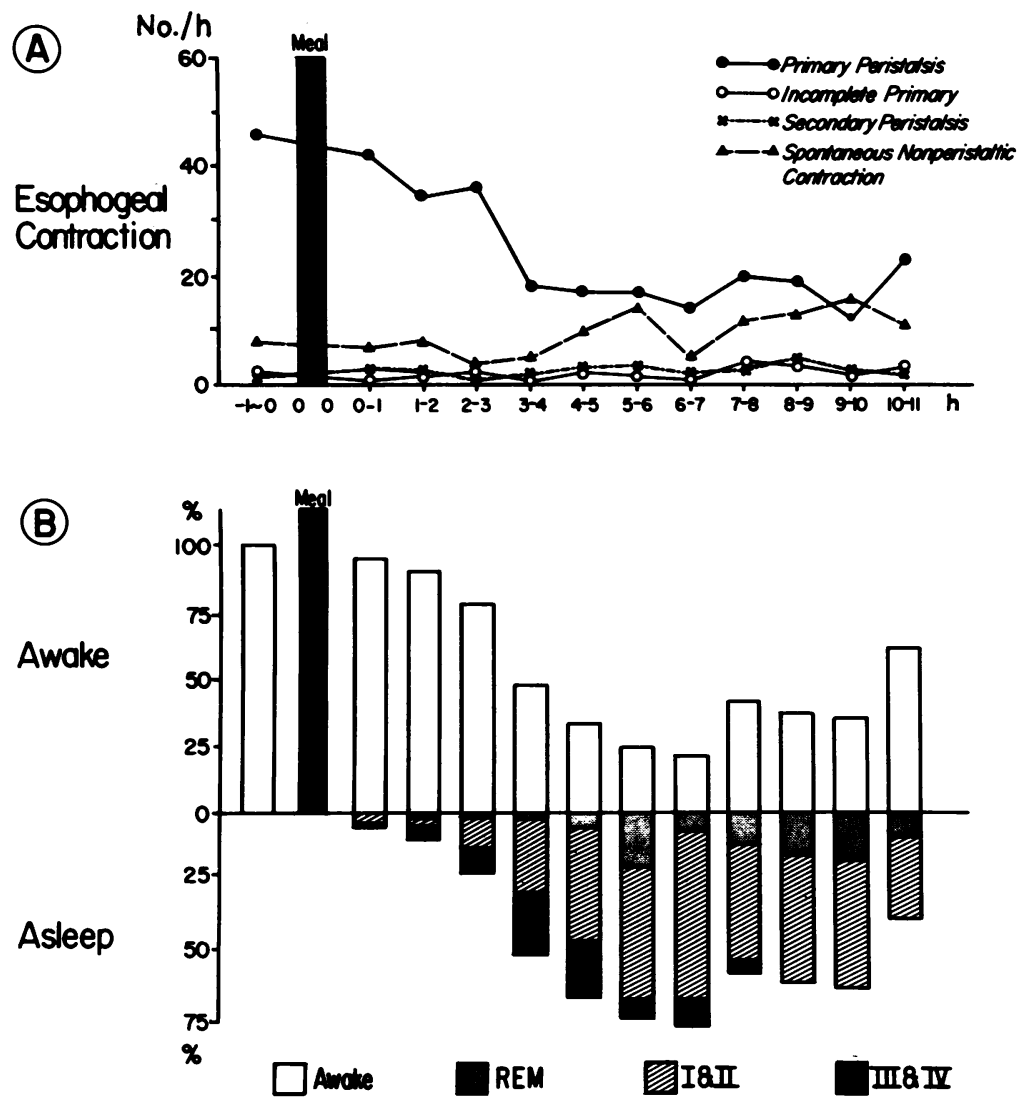

FIGURE 10 Relationship of contractions in the esophageal body to intervals of wakefulness and stages of sleep in 10 subjects monitored for $12 \mathrm{~h}$. Each subject lay recumbent during monitoring. (A) Esophageal contractions. Swallow-induced primary peristalsis occurred nearly once a minute while the subjects were awake, but decreased to about $20 / \mathrm{h}$ during the night. The rate of incomplete primary peristaltic sequences and secondary peristalsis, $3-5 / \mathrm{h}$, remained constant. Spontaneous, nonperistaltic contractions tended to increase in frequency during the night. (B) Cumulative scores of wakefulness and sleep states for each hour of study. Before the meal, all the subjects were awake. During the first $3 \mathrm{~h}$ after eating most of the subjects remained fully awake, but several dozed. Beginning the 4th $\mathrm{h}$ after the meal, about 10:30 p.m., when the room lights were switched off, the subjects slept for $50 \%$ or more of each hour except the last hour of the study when the percentage decreased to $35 \%$. Deep sleep, stages III and IV, occurred primarily during the early part of the night, whereas REM sleep became more prominent later in the night. 
TABLE IV

Types of Esophageal Contractions Occurring per Hour during the Awake and Sleep States in 10 Volunteer Subjects*

\begin{tabular}{lcccc}
\hline & Awake & \multicolumn{3}{c}{ Sleep stages } \\
\cline { 4 - 5 } Type of contraction & state & REM & I and II & III and IV \\
\hline $\begin{array}{c}\text { Primary } \\
\text { peristalsis }\end{array}$ & $45 \pm 5$ & $2 \pm 2$ & $2 \pm 1$ & $1 \pm 1$ \\
$\begin{array}{c}\text { Incomplete } \\
\text { peristalsis }\end{array}$ & $4 \pm 2$ & 0 & $0.1 \pm 0.1$ & 0 \\
$\begin{array}{c}\text { Secondary } \\
\text { peristalsis }\end{array}$ & $3 \pm 1$ & $3 \pm 1$ & $1 \pm 1$ & 0 \\
$\begin{array}{c}\text { Spontaneous } \\
\text { nonperistaltic }\end{array}$ & $12 \pm 6$ & $18 \pm 5$ & $4 \pm 1$ & $0.1 \pm 0.1$ \\
\hline
\end{tabular}

* Values are mean $\pm \mathrm{SE}$ events per hour.

spontaneously or after a completed peristaltic sequence have no initiating signal identified by the manometric method. Perhaps neural pathways responsible for LESR are not linked in an all-or-none fashion to the pathways governing esophageal peristalsis. Thus, a pharyngeal stimulus subthreshold for triggering a swallow might, in some instances, elicit LESR. In the opossum, we have observed that light stroking of the pharynx may partially relax the LES at a stimulus below the threshold needed to induce swallowing (unpublished observations). Similar observations have been made in the cat (24) and dog (25). Conceivably, sensory stimuli from areas other than the pharynx, for example, from the stomach, or esophageal body, might also incite LESR through autonomic neural pathways that are not yet identified. Clearly, further study is needed to determine the mechanism(s) governing the inappropriate LESR observed in this study.

Our study findings confirm that the main mechanism responsible for acid clearance from the esophagus in recumbent subjects is esophageal peristalsis $(1,26)$. Peristaltic sequences after acid reflux generally caused step-like elevations of esophageal $\mathrm{pH}$ until the $\mathrm{pH}$ was restored to its pre-reflux value. Incomplete peristaltic sequences and simultaneous nonperistaltic contractions that occurred after acid reflux were less effective in restoring esophageal $\mathrm{pH}$ than primary or secondary peristalsis. Thus, failure of peristalsis to occur results in delayed esophageal clearance and prolonged exposure to acid. Acid esophageal $\mathrm{pH}$ climbed very slowly between peristaltic sequences. This gradual rise in $\mathrm{pH}$ could be caused by either buffering from esophageal secretions or leakage of hydrogen ion across the esophageal mucosa.

The observation that primary peristalsis predominated over secondary peristalsis in clearing the esophagus of refluxed acid was not anticipated. Although the frequency of secondary peristalsis increased significantly after reflux, the incidence of primary peri- stalsis while esophageal $\mathrm{pH}$ was $<4$ still exceeded that of secondary peristalsis. This finding appears to be explained by the high frequency of swallows maintained during the awake state, about $1 / \mathrm{min}$, irrespective of whether or not GE reflux occurs. Thus, two mechanisms that generate peristalsis appear to protect the esophagus against refluxed acid: $(a)$ an increase in the rate of secondary peristalsis, probably elicited by esophageal stretch, and $(b)$ the high probability that primary peristalsis will occur soon after reflux because of the high natural frequency of swallowing in the awake state. When esophageal $\mathrm{pH}$ was 2.0 or less the combined rate of primary and secondary peristalsis was $4.1 / \mathrm{min}$ compared to $0.9 / \mathrm{min}$ when esophageal $\mathrm{pH}$ was $>4$.

Our findings on the relationship of sleep to esophageal motility, gastroesophageal reflux, and esophageal clearance are in accord with the limited information available from other studies. Nocturnal periods of infrequent or absent swallowing have often been assumed to be associated with sleep (27). In one study of normal subjects using EEG to monitor sleep, the author established that stable sleep was associated with a low incidence of primary peristalsis (26). The present study confirms that swallowing occurs infrequently during sleep. The occurrence of volleys of swallows between sleep periods has also been noted previously in association with brief arousals from sleep or more prolonged periods of wakefulness (26). Such clusters of swallows do not appear to be caused by the presence of a recording assembly in the pharynx because earlier studies have monitored swallowing by techniques not requiring intubation $(26,27)$. The reason for the relatively high frequency of spontaneous, nonperistaltic esophageal contractions during REM sleep is not clear. Our results show, however, that such contractions are not a very effective mechanism for clearing the esophagus of acid material.

When sleep supervened in our normal subjects before refluxed acid was cleared from the esophagus, the low incidence of esophageal peristaltic activity during sleep favored a prolonged esophageal exposure to acid. Such periods of extended esophageal exposure to acid during sleep have been noted by other workers in normal subjects (13) as well as patients with esophagitis $(1,14,28)$. Similar to the finding of this study, Lichter (1) also observed a low incidence of esophageal peristalsis during periods of prolonged acid exposure. In patients with esophagitis it is possible that a high incidence of reflux and perhaps a suboptimal peristaltic clearance of acid increase the chances of acid being present in the esophagus at the onset of sleep intervals.

\section{ACKNOWLEDGMENTS}

Supported, in part, by National Institutes of Health grant 15540 and by a grant from the Clinical Research Centers program PR 58. 


\section{REFERENCES}

1. Lichter, I. 1974. Measurement of gastro-oesophageal acid reflux: its significance in hiatus hernia. Br. J. Surg. 61: 253-258.

2. Dodds, W. J., W. J. Hogan, and W. N. Miller. 1976. Reflux esophagitis. Am. J. Dig. Dis. 21: 49-67.

3. Dodds, W. J. 1976. Instrumentation and methods for intraluminal esophageal manometry. Arch. Int. Med. 136: 515-523.

4. Cohen, S., and L. D. Harris. 1972. The lower esophageal sphincter. Gastroenterology. 63: 1066-1073.

5. Rechtschaffen, A., and A. Kales. 1968. A Manual of Standardized Terminology Techniques and Scoring System for Sleep Stages of Human Subjects. U. S. Department of Health, Education, and Welfare, Bethesda, Md. Publication No. 204.

6. Williams, H. L., J. T. Hamonack, R. L. Daly, W. C. Dement, and A. Lubin. 1964. Responses to auditory stimulation sleep loss and the EEG stages of sleep. Electroencephalogr. Clin. Neurophysiol. 16: 269-279.

7. Dent, J. 1976. A new technique for continuous sphincter pressure measurement. Gastroenterology. 71: 263-267.

8. Dodds, W. J., E. T. Stewart, D. Hodges, and F. F. Zboralske. 1973. Movement of the feline esophagus associated with respiration and peristalsis. J. Clin. Invest. 52: 1-13.

9. Dodds, W. J., E. T. Stewart, W. J. Hogan, J. J. Stef, and R. C. Arndorfer. 1974. Effect of esophageal movement on intraluminal esophageal pressure recording. Gastroenterology. 67: 592-600.

10. Arndorfer, R. C., J. J. Stef, W. J. Dodds, J. H. Linehan, and W. J. Hogan. 1977. Improved infusion system for intraluminal esophageal manometry. Gastroenterology. 73: 23-27.

11. Butterfield, D. G., J. E. Struthers, and B. S. Showalter. 1972. A test of gastroesophageal sphincter competence. The common cavity test. Am. J. Dig. Dis. 17: 415-421.

12. Johnson, L. F., and T. R. Demeester. 1974. Twenty-fourhour pH monitoring of the distal esophagus. Am. J. Gastroenterol. 62: 325-332.

13. Boesby, S. 1975. Gastro-oesophgeal acid reflux and sphincter pressure in normal human subjects. Scand. J. Gastroenterol. 10: 731-736.

14. Demeester, T. R., L. F. Johnson, G. J. Joseph, M. S. Tos- cano, A. W. Hall, and D. B. Skinner. 1976. Patterns of gastroesophageal reflux in health and disease. Ann. Surg. 184: 459-470.

15. Kaye, M. D. 1977. Postprandial gastro-oesophageal reflux in healthy people. Gut. 18: 709-712.

16. Nagler, R., and H. Spiro. 1963. Persistent gastroesophageal reflux induced during prolonged gastric intubation. N. Engl. J. Med. 269: 495-500.

17. Vinnik, I., and F. Kern. 1964. The effect of gastric intubation on esophageal pH. Gastroenterology. 57: 388.

18. Fisher, R. S., L. S. Malmud, G. S. Roberts, and I. F. Lobis. 1976. Gastroesophageal (GE) scintiscanning to detect and quantitate GE reflux. Gastroenterology. 70: 301-308.

19. Kaufman, S. E., and M. D. Kaye. 1978. Induction of gastro-oesophageal reflux by alcohol. Gut. 19: 336-338.

20. Skinner, D. B., and T. F. Camp, Jr. 1968. Relation of esophageal reflux to lower esophageal sphincter pressures decreased by atropine. Gastroenterology. 54: 543551.

21. Kantrowitz, P. A., J. G. Corson, D. J. Fleischli, and D. B. Skinner. 1969. Measurement of gastroesophageal reflux. Gastroenterology. 56: 666-674.

22. Miller, W. N., K. P. Ganeshappa, W. J. Dodds, W. J. Hogan, R. F. Barreras, and R. C. Arndorfer. 1977. Effect of bethanechol on gastroesophageal reflux. Am. J. Dig. Dis. 22: 230234.

23. Longhi, E. H., and H. Jordan. 1969. Pressure relationships responsible for reflux in patients with hiatal hernia. Surg. Gynecol. Obstet. 129: 734-738.

24. Carlson, A. J., T. E. Boyd, and J. F. Pearcy, 1923. Studies on the visceral sensory nervous system. XIV The reflex control of the cardia and lower esophagus in mammals. Arch. Int. Med. 30: 409-433.

25. Zeller, W., and G. E. Burget. 1937. A study of the cardia. Am. J. Dig. Dis 4: 113-120.

26. Lichter, I., and R. C. Muir. 1975. The pattern of swallowing during sleep. Electroencephalogr. Clin. Neurophysiol. 38: 427-432.

27. Lear, C. S. C., J. B. Flanagan, Jr., and C. F. A. Moorrees. 1965. The frequency of deglutition in man. Arch. Oral. Biol. 10: 83-99.

28. Pattrick, F. G. 1970. Investigation of gastroesophageal reflux in various positions with a two-lumen $\mathrm{pH}$ electrode. Gut. 11: 659-667. 